\title{
Two Modes of Gulf Stream Variability Revealed in the Last Two Decades of Satellite Altimeter Data
}

\author{
M. DOLORES PÉREZ-HERNÁNDEZ \\ Instituto de Oceanografía y Cambio Global, Universidad de Las Palmas de Gran Canaria, Las Palmas, Spain \\ TERRENCE M. JOYCE \\ Department of Physical Oceanography, Woods Hole Oceanographic Institution, Woods Hole, Massachusetts
}

(Manuscript received 20 June 2013, in final form 8 September 2013)

\begin{abstract}
Monthly mapped sea level anomalies (MSLAs) of the NW Atlantic in the region immediately downstream of the Gulf Stream (GS) separation point reveal a leading mode in which the path shifts approximately $100 \mathrm{~km}$ meridionally about a nominal latitude of $39^{\circ} \mathrm{N}$, producing coherent sea level anomaly (SLA) variability from $72^{\circ}$ to $50^{\circ} \mathrm{W}$. This mode can be captured by use of a simple 16-point index based on SLA data taken along the maximum of the observed variability in the region $33^{\circ}-46^{\circ} \mathrm{N}$ and $45^{\circ}-75^{\circ} \mathrm{W}$. The GS shifts between 2010 and 2012 are the largest of the last decade and equal to the largest of the entire record. The second group of EOF modes of variability describes GS meanders, which propagate mainly westward interrupted by brief periods of eastward or stationary meanders. These meanders have wavelengths of approximately $400 \mathrm{~km}$ and can be seen in standard EOFs by spatial phase shifting of a standing meander pattern in the SLA data. The spectral properties of these modes indicate strong variability at interannual and longer periods for the first mode and periods of a few to several months for the meanders. While the former is quite similar to a previous use of the altimeter for GS path, the simple index is a useful measure of the large-scale shifts in the GS path that is quickly estimated and updated without changes in previous estimates. The time-scale separation allows a lowpass filtered 16-point index to be reflective of large-scale, coherent shifts in the GS path.
\end{abstract}

\section{Introduction}

The Gulf Stream (GS) is the western boundary of the North Atlantic subtropical gyre. The GS emerges from the Florida Straits and flows northward to Cape Hatteras where the stream no longer follows the shelf break and continues to the northeast into the deep waters. After the GS leaves the continental shelf fluctuations have been characterized as meanders and lateral large-scale shifts (Lee and Cornillon 1995). Meanders are thought to be related to internal (baroclinic and/or barotropic) instabilities of the GS (Lee and Cornillon 1995).

The low frequency, interannual north-south movements of the GS has been explained by various mechanisms:

Corresponding author address: M. D. Pérez-Hernández, Instituto de Oceanografía y Cambio Global, Edificio de Ciencias Básicas, Campus de Tafira, Universidad de Las Palmas de Gran Canaria, Las Palmas, 35017, Spain.

E-mail: mdolores.perez@ulpgc.es westward-traveling long baroclinic oceanic Rossby waves (Gangopadhyay et al. 1992); variable southward flow of the Labrador surface water found on the North Carolina shelf (Rossby and Benway 2000; Hameed 2004; Peña-Molino and Joyce 2008); variable southwardflowing slope water and Deep Western Boundary Current (DWBC) within the northern recirculation gyre of the GS (Lee and Cornillon 1995; Joyce et al. 2000; Zhang and Vallis 2006); response of the intergyre boundary to wind curl variability associated with North Atlantic Oscillation (NAO) phases (Lee and Cornillon 1995; Taylor et al. 1998; Marshall et al. 2001); and by El Niño-Southern Oscillation (ENSO) (Lee and Cornillon 1995; Taylor et al. 1998).

The GS position has been recorded in many ways, such as the use of the $15^{\circ} \mathrm{C}$ isotherm at $200 \mathrm{~m}$ (Gangopadhyay et al. 1992; Fuglister 1955; Joyce et al. 2000), or, using altimetry, by searching for the maximum along-track SSH gradient (Kelly and Gille 1990; Frankignoul et al. 2001; Peña-Molino and Joyce 2008; Lillibridge and Mariano 2012). 


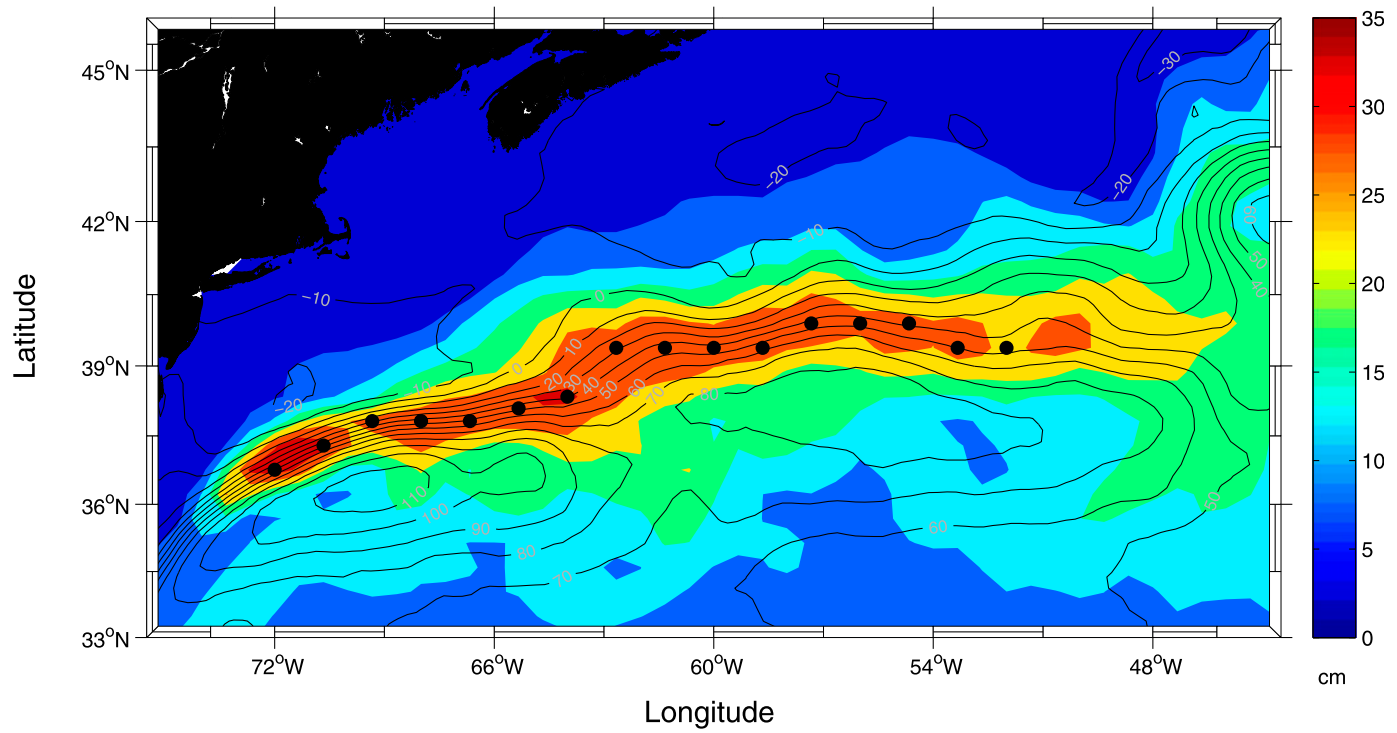

FIG. 1. Position of the array of 16 points (black dots). Black contour lines show the distribution of MDT (every $10 \mathrm{~cm}$ ) and the colored field is the standard deviation of the monthly SLA $(\mathrm{cm})$.

GS meanders are affected by Rossby wave dynamics, which, in the absence of a background flow, forces them to propagate westward most of the time (Gangopadhyay et al. 1992; Bower and Hogg 1992; Lee and Cornillon 1995; Taylor et al. 1998; Nakamura and Chao 2000; Osychny and Cornillon 2004). At the same time, the GS exerts its influence over them too, advecting them eastward (Bane et al. 1981; Watts and Johns 1982; Bower 1989; Savidge 2004). When these opposing influences balance, one might expect quasi-stationary meanders that have been observed sometimes during extended periods of almost a year (Nakamura and Chao 2000; Savidge 2004).

In what follows, a study of the GS shifts and meanders is addressed using two decades of satellite altimeter data. The study will estimate the principal components and frequencies of the GS path variability and demonstrate the utility of a simple 16-point GS index. The following section will describe the data and methodology used. Then, results are shown in section 3 and discussed in section 4 .

\section{Data and methods}

Gridded sea level anomalies (MSLA) weekly data from October 1992 to October 2012 were downloaded together with the mean dynamic topography (MDT) from the Archiving, Validation, and Interpretation of Satellite Oceanographic data (AVISO) remote sensing service (http://www.aviso.oceanobs.com/). They were averaged per month and analyzed within the region of the newly separated GS: $33^{\circ}-46^{\circ} \mathrm{N}$ and $45^{\circ}-75^{\circ} \mathrm{W}$. To avoid large annual steric signals in the data, the monthly mean was subtracted from each corresponding month at every observational grid point.

The simple 16-point GS index is constructed by selecting grid points following the maximum standard deviation of sea level anomalies (SLA), every $1.33^{\circ}$ longitude between $52^{\circ}$ and $72^{\circ} \mathrm{W}$ and averaging them. In Fig. 1, the MDT and the standard deviation of the monthly SLA are shown together with the position of the 16 selected points of SLA (Table 1). The monthly mean signal removed from the data is shown in Fig. 2, revealing a seasonal steric heating that expands the ocean as it heats and is uniform and broad scale, with no basic difference between the array of 16 points and the whole area average values (Fig. 2, error bars).

TABLE 1. Position of the array of 16 points.

\begin{tabular}{ll}
\hline \hline Lat $(\mathrm{N})$ & Lon $(\mathrm{W})$ \\
\hline $36.7588^{\circ}$ & $72.0000^{\circ}$ \\
$37.2911^{\circ}$ & $70.6667^{\circ}$ \\
$37.8196^{\circ}$ & $69.3333^{\circ}$ \\
$37.8196^{\circ}$ & $68.0000^{\circ}$ \\
$37.8196^{\circ}$ & $66.6667^{\circ}$ \\
$38.3443^{\circ}$ & $65.3333^{\circ}$ \\
$38.3443^{\circ}$ & $64.0000^{\circ}$ \\
$39.3825^{\circ}$ & $62.6667^{\circ}$ \\
$39.3825^{\circ}$ & $61.3333^{\circ}$ \\
$39.3825^{\circ}$ & $60.0000^{\circ}$ \\
$39.3825^{\circ}$ & $58.6667^{\circ}$ \\
$39.8959^{\circ}$ & $57.3333^{\circ}$ \\
$39.8959^{\circ}$ & $56.0000^{\circ}$ \\
$39.8959^{\circ}$ & $54.6667^{\circ}$ \\
$39.3825^{\circ}$ & $53.3333^{\circ}$ \\
$39.3825^{\circ}$ & $52.0000^{\circ}$ \\
\hline
\end{tabular}




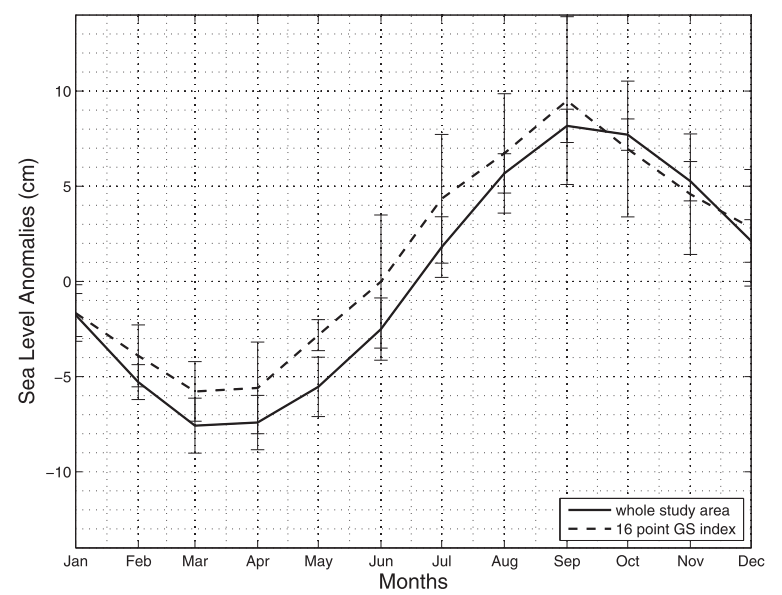

FIG. 2. Monthly mean SLA (cm) for the whole study area (solid line) and for the 16-point GS index (dashed line) together with their error bars.

An empirical orthogonal function (EOF) analysis, also known as principal component analysis, is applied to the study area and to the array of 16 GS points. As it is a temporal EOF, the temporal mean (the mean of each coordinate) is first subtracted from each data point (Hernández-Guerra and Nykjaer 1997). EOF analysis distributes the total variance among a series of eigenvectors, each of which contains a percentage of the variability of the data (Preisendorfer and Mobley 1988). This way we can distinguish the dominant patterns from the remaining variability, which is treated as noise. Each mode of an EOF decomposition is composed of a space-time pattern whose amplitudes are described as

$$
\mathbf{D}(x, t)=\mathbf{A}(x) \mathbf{V}^{\mathrm{T}}(t),
$$

where $\mathbf{D}$ is the $M \times N$ matrix of $M$ spatial points and $N$ temporal points, $\mathbf{A}(x)$ is the matrix of amplitude functions that describes the spatial distribution of the variance of a given mode, and $\mathbf{V}^{\mathrm{T}}(t)$ is the transposed matrix of amplitude functions which shows the variation of each mode in time. Following Overland and Preisendorfer (1982) a Monte Carlo method is employed to find which EOF's modes are above the noise level. This method states that those modes that have higher percent of variance than the error percentage of variance obtained from the Monte Carlo are those over the noise level.

To study the periodicity of the first modes, the Welch method of spectral analysis is used. This method estimates power spectra, sectioning the record, taking modified periodograms of these sections and averaging them

TABLE 2. First percentages of variance accounted for the array of 16 points and for the whole region (the Percentage and Cumulative percentage columns) and the error percentage arising from the rule of Overland and Preisendorfer (1982) (the Error percentage column).

\begin{tabular}{|c|c|c|c|c|}
\hline & Mode & Percentage & Cumulative percentage & Error percentage \\
\hline \multirow[t]{4}{*}{ Array of 16 points } & 1 & $37.6 \%$ & $37.6 \%$ & $13.6 \%$ \\
\hline & 2 & $15.5 \%$ & $53.1 \%$ & $11.6 \%$ \\
\hline & 3 & $14.6 \%$ & $67.7 \%$ & $10.2 \%$ \\
\hline & 4 & $8.3 \%$ & $76.0 \%$ & $9.1 \%$ \\
\hline \multirow[t]{21}{*}{ Whole study area } & 1 & $18.9 \%$ & $18.9 \%$ & $1.6 \%$ \\
\hline & 2 & $10.6 \%$ & $29.6 \%$ & $1.5 \%$ \\
\hline & 3 & $9.4 \%$ & $38.9 \%$ & $1.5 \%$ \\
\hline & 4 & $6.9 \%$ & $45.9 \%$ & $1.4 \%$ \\
\hline & 5 & $5.3 \%$ & $51.2 \%$ & $1.4 \%$ \\
\hline & 6 & $4.5 \%$ & $55.7 \%$ & $1.4 \%$ \\
\hline & 7 & $4.0 \%$ & $59.7 \%$ & $1.4 \%$ \\
\hline & 8 & $3.9 \%$ & $63.5 \%$ & $1.3 \%$ \\
\hline & 9 & $3.3 \%$ & $66.8 \%$ & $1.3 \%$ \\
\hline & 10 & $2.7 \%$ & $69.6 \%$ & $1.3 \%$ \\
\hline & 11 & $2.7 \%$ & $72.2 \%$ & $1.3 \%$ \\
\hline & 12 & $2.6 \%$ & $74.5 \%$ & $1.2 \%$ \\
\hline & 13 & $2.3 \%$ & $76.5 \%$ & $1.2 \%$ \\
\hline & 14 & $2.0 \%$ & $78.2 \%$ & $1.2 \%$ \\
\hline & 15 & $1.7 \%$ & $79.8 \%$ & $1.2 \%$ \\
\hline & 16 & $1.6 \%$ & $81.3 \%$ & $1.2 \%$ \\
\hline & 17 & $1.5 \%$ & $82.8 \%$ & $1.1 \%$ \\
\hline & 18 & $1.5 \%$ & $84.1 \%$ & $1.1 \%$ \\
\hline & 19 & $1.2 \%$ & $85.3 \%$ & $1.1 \%$ \\
\hline & 20 & $1.2 \%$ & $86.3 \%$ & $1.1 \%$ \\
\hline & 21 & $1.0 \%$ & $87.2 \%$ & $1.1 \%$ \\
\hline
\end{tabular}


Mode 1
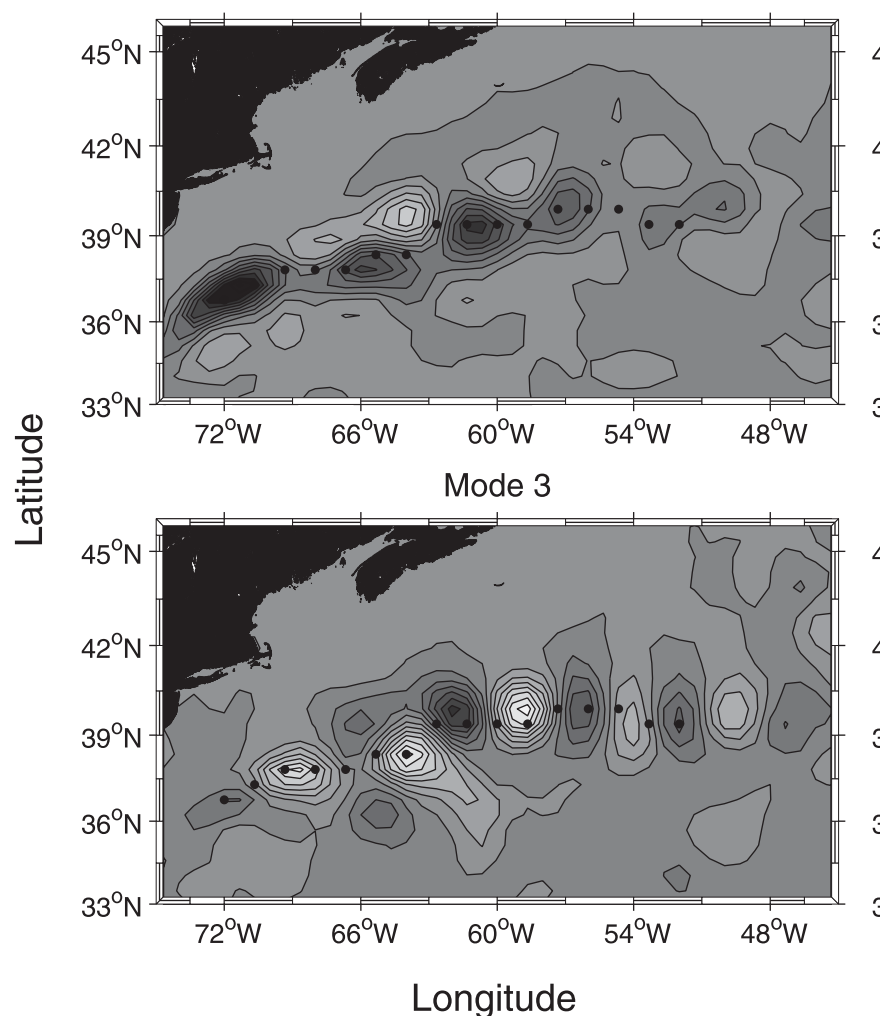
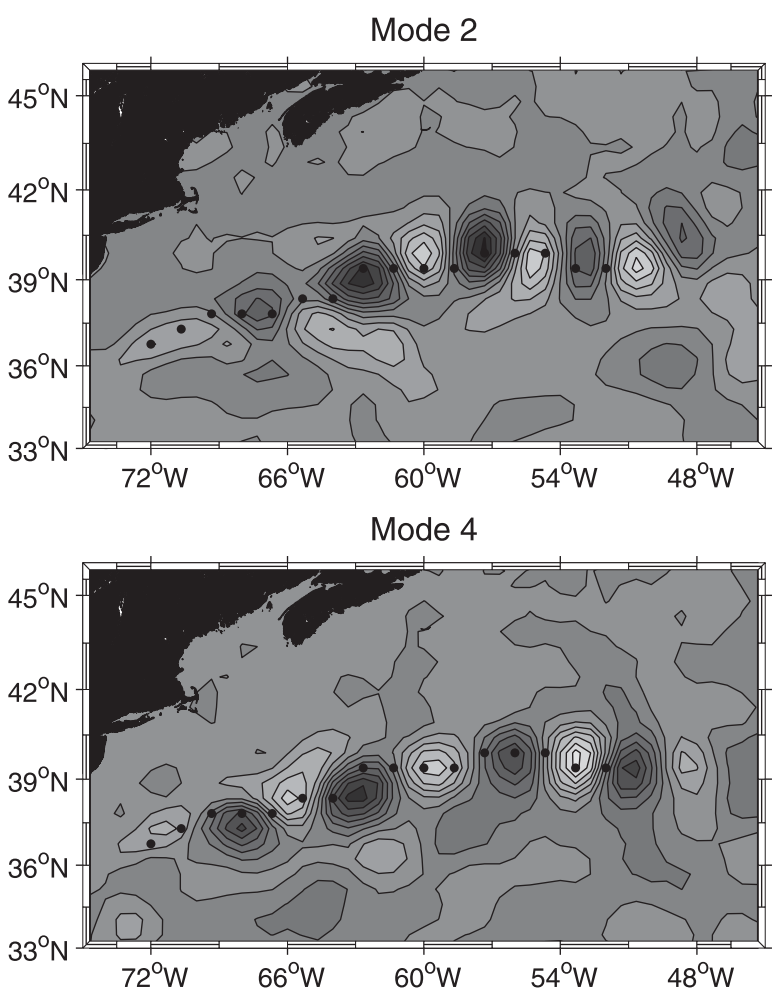

Longitude

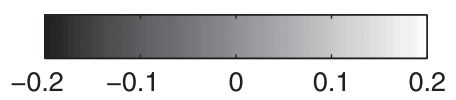

FIG. 3. Spatial amplitudes of the first modes of the whole study area (gray shades) and position of the array of 16 points (black dots).

(Welch 1967). The Welch method employed has a 128 month Hamming window with a $50 \%$ of overlap between consecutive data segments of 108 months. A sensitive analysis was done using 120 and 108 month Hamming windows, and there were not significant differences in the resulting frequency peaks. Modes were standardized before the analysis and rescaled afterward based on their percentage of the total variance.

\section{Results}

Looking into Fig. 1 where the MDT is found, we can observe that the maximum standard deviation of SLA is coincident with the maximum mean flow: thus positive anomalies will be associated with northward shifts of the local GS and vice versa. Table 2 reflects the percentages of the lowest EOF modes of the array of 16 points and whole study region. Following the rule of Overland and Preisendorfer (1982), for the array of 16 points, only three modes are above the noise level, while for the whole region the first 20 modes are significant (Table 2, Error percentage column).
The spatial amplitudes of the four first modes of the whole SLA data shown in Fig. 1 (hereafter whole study area) are shown in Fig. 3. These modes represent 45.9\% of the total SLA variance. The first mode reveals high negative anomalies nearly everywhere, with largest amplitudes along the array of 16 points. This connected negative structure comprises a meridional shift of the GS. Anywhere else, most of the amplitudes of mode 1 are not significantly different from zero.

The temporal variation of the lowest, path-shifting, mode (Fig. 4 ) of the array of 16 points $(37.6 \%$ of variance; Fig. 4, top) and the whole region (18.9\% of variance; Fig. 4, bottom) are quite similar and similar to a simple index created from the mean of the 16-point SLA (hereafter simple 16-point GS index). The correlation between the first mode of the array of 16 points and this average index is 0.90 . The whole study area mode 1 is also very well correlated with the average index $(0.83)$ and with the first mode of the array of 16 points $(0.93)$. This first mode characterizes the north-south shifts of the GS and is plotted such that positive values are associated with northward GS displacements. During July 


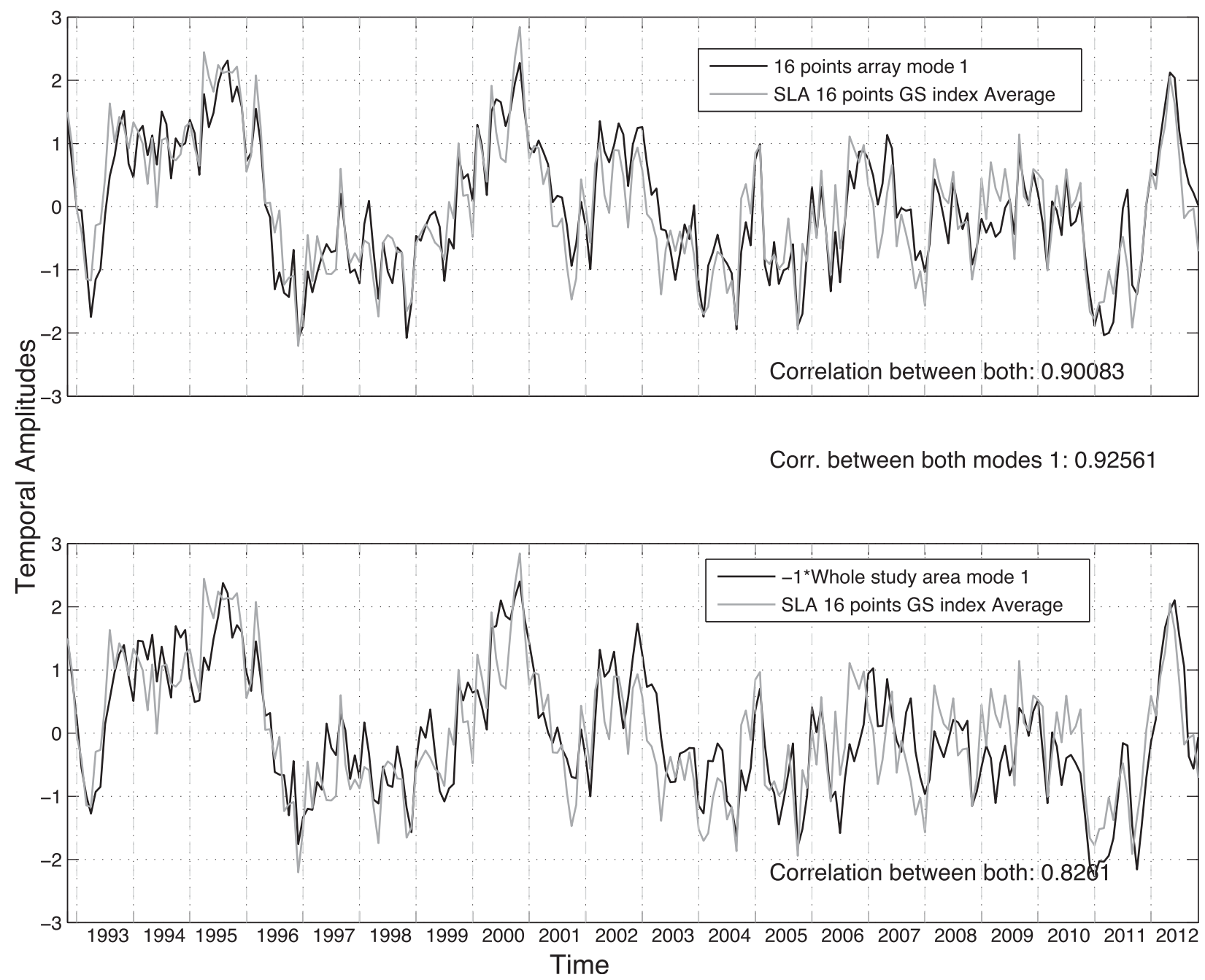

FIG. 4. Standardized temporal amplitudes of (top) the first modes of the array of 16 points (dark line) and (bottom) the whole study area (dark line), each together with the 16-point GS index (light lines). The correlations between them are also shown.

1995, October 2000, and April 2012 the GS was in its most northward position, shifting between 50 and $110 \mathrm{~km}$ from its mean position.

In contrast, the other modes shown in Fig. 3 exhibit alternating high positive to negative structures, again with largest magnitudes through the array of 16 points. Meanders are associated with instability processes and large-scale lateral shifts of the path due to atmospheric forcing. The whole area modes 2 and 3 are shown in Fig. 5. These modes combined contain the $20 \%$ of the total variance of the whole study area. Modes 2 and 3 illustrate mesoscale behavior occurring along the GS mean path, with the maxima and minima of mode 2 roughly coincident with the largest spatial rate of change of mode 3 (Fig. 5, modes 2 and 3). The temporal amplitudes of these patterns are not well correlated with the simple 16-point GS index, having a 0.19 correlation with mode 2 and of 0.20 with mode 3 . Even though both modes are orthogonal in time, they seem to be different phases of the same phenomenon, suggesting a propagating signal.

Results from the Welch method for spectral analysis of the first three standardized modes of the whole study area are shown in Fig. 6. In this figure, the modes were rescaled according to their percentage of total variance. Mode 1 exhibits its higher peaks at periods of approximately 5 and 2 yr (64 and 25.6 months) (Fig. 6, top). The approximately 2 -yr energy band has been previously documented in Peña-Molino and Joyce (2008).

The three modes each show peaks near annual periods (11.64-16 months; Fig. 6). After those peaks, the next peaks are at near semiannual periods and slightly higher: 7.53 (mode 1$), 9.14,6.74(\operatorname{mode} 2)$, and of 9.85, 8 (mode 3$)$ months (Fig. 6). 


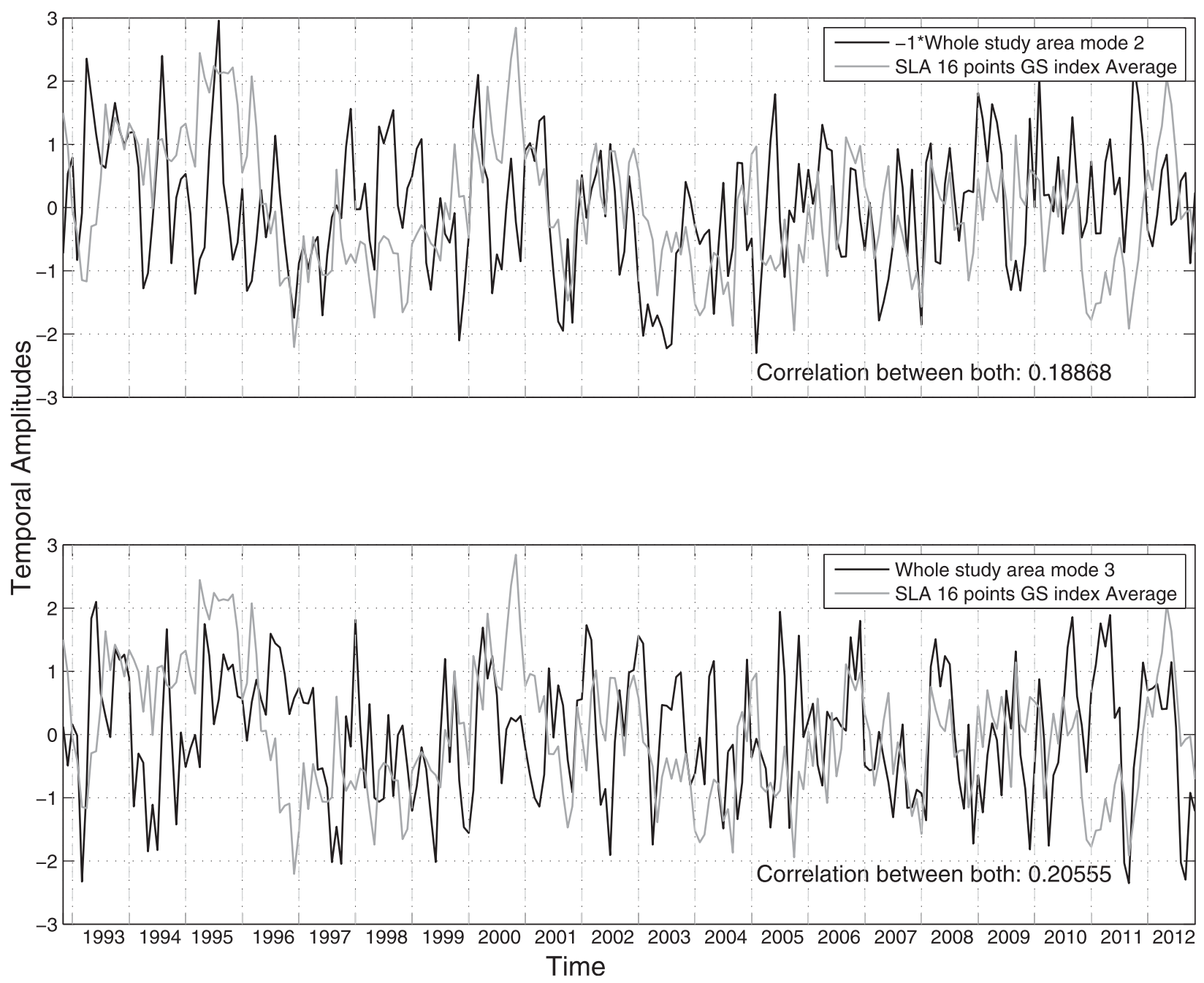

FIG. 5. Standardized temporal amplitudes of the second and third modes of the whole study area (dark lines), together with the SLA of the 16-point GS index (light lines). The correlations between each mode and the average are shown.

The remaining frequency peaks of mode 1 represent the interannual variability while the weaker peaks observed in modes 2 and 3 (Fig. 6, middle and bottom) are between the periods 1 and 6 months.

To study how those meanders contained in modes 2,3 , and 4 propagate (Fig. 3), a Hovmöller diagram is constructed (Fig. 7) based entirely on the reconstructed time series from the three meander EOF modes. From $75^{\circ}$ to $65^{\circ} \mathrm{W}$, a low energy area can be distinguished in both plots. Figure 7 reveals a westward propagation pattern, broken by limited periods of eastward and stationary meanders. The first evidence of quasi-steady meanders appears in Fuglister and Worthington (1951) where near Nova Scotia they found large-amplitude meanders that were quasi stationary and characterized by a slowly evolving baroclinic field, indicating temporal growth. Eastward or downstream meander propagation has been recorded in the vicinity of Cape Hatteras (Bane et al. 1981).

\section{Discussion}

Taking the maximum standard deviation of SLA every $1.33^{\circ}$ of longitude, a 16-point GS index to measure the latitudinal shifts of the GS is constructed (Fig. 1). This index is well correlated with the whole study area mode 1 (monthly 0.8 , low-pass filtered 0.9 ). In comparison with other ways to measure the GS path, this index considerably simplifies computations and provides an index which will not change past values as new data are added, unlike traditional EOF indices. A common way to define the region of strong flow of the GS is the temperature at 200-m depth (Fuglister 1955; Joyce et al. 2000). The $15^{\circ} \mathrm{C}$ isotherm at $200 \mathrm{~m}[\mathrm{~T}(200)]$ is in the 
Whole study area mode 1
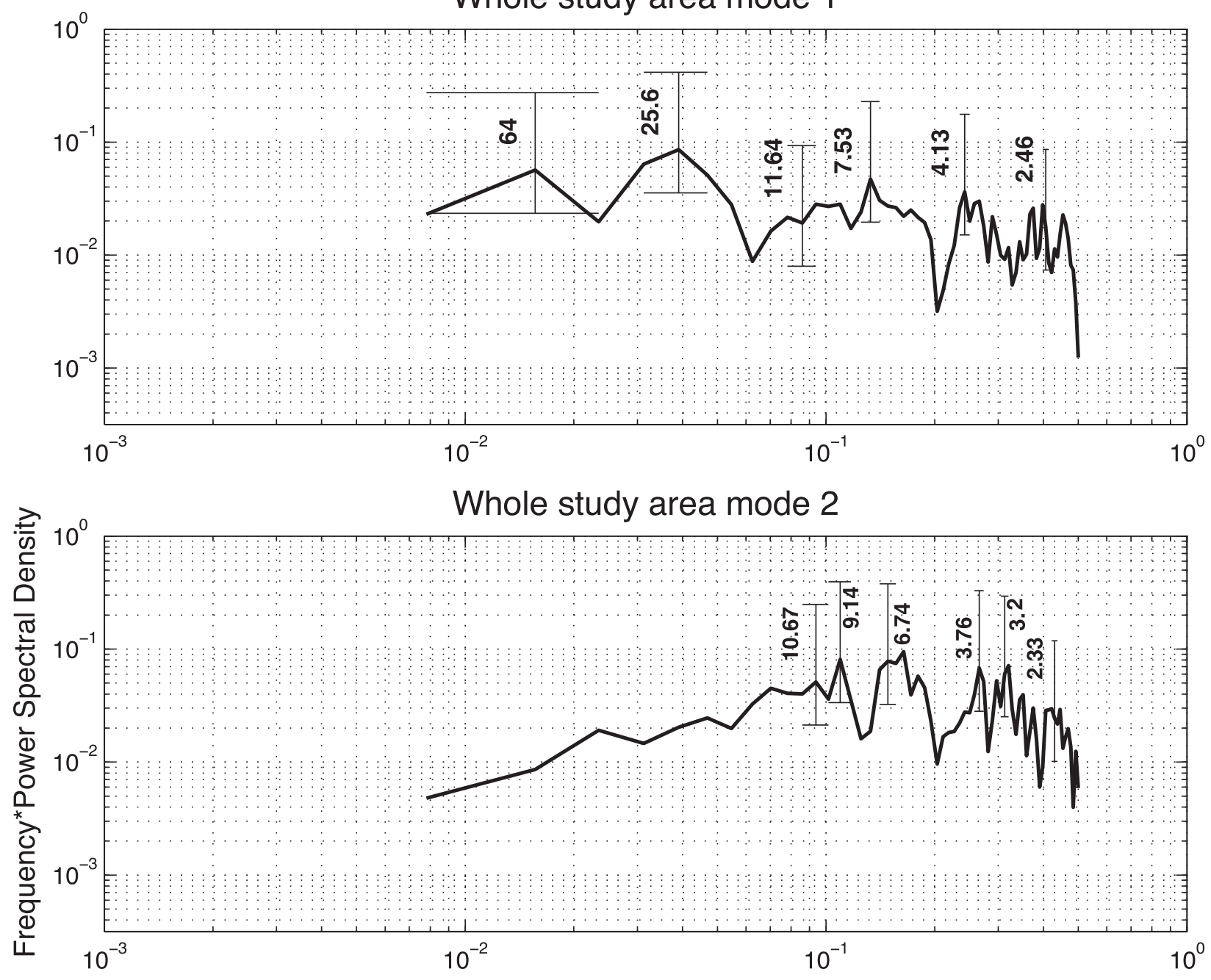

Whole study area mode 3

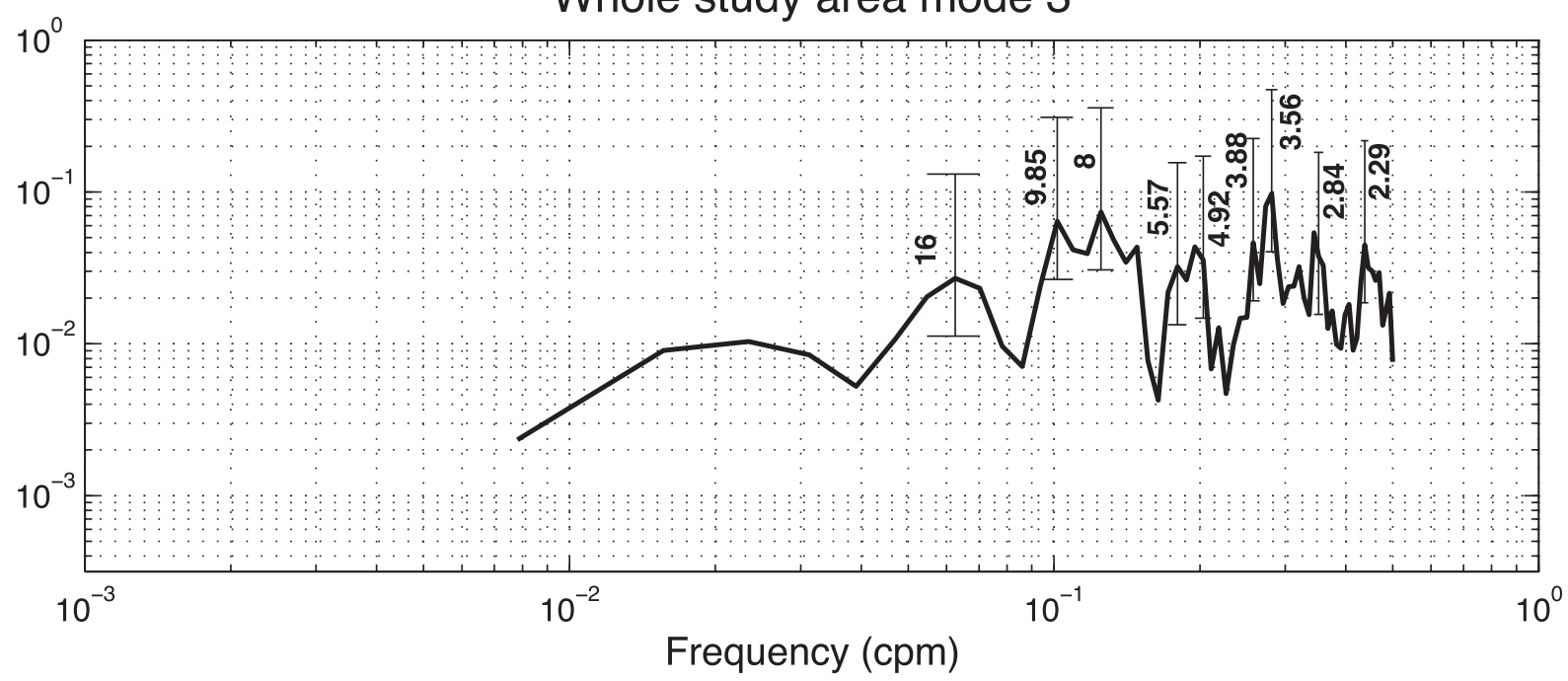

FIG. 6. Results of the Welch spectral analysis of the whole study area modes 1,2 , and 3 . The frequency units are cycles per month since the standardized modes are scaled to their percentage of the total variance. 


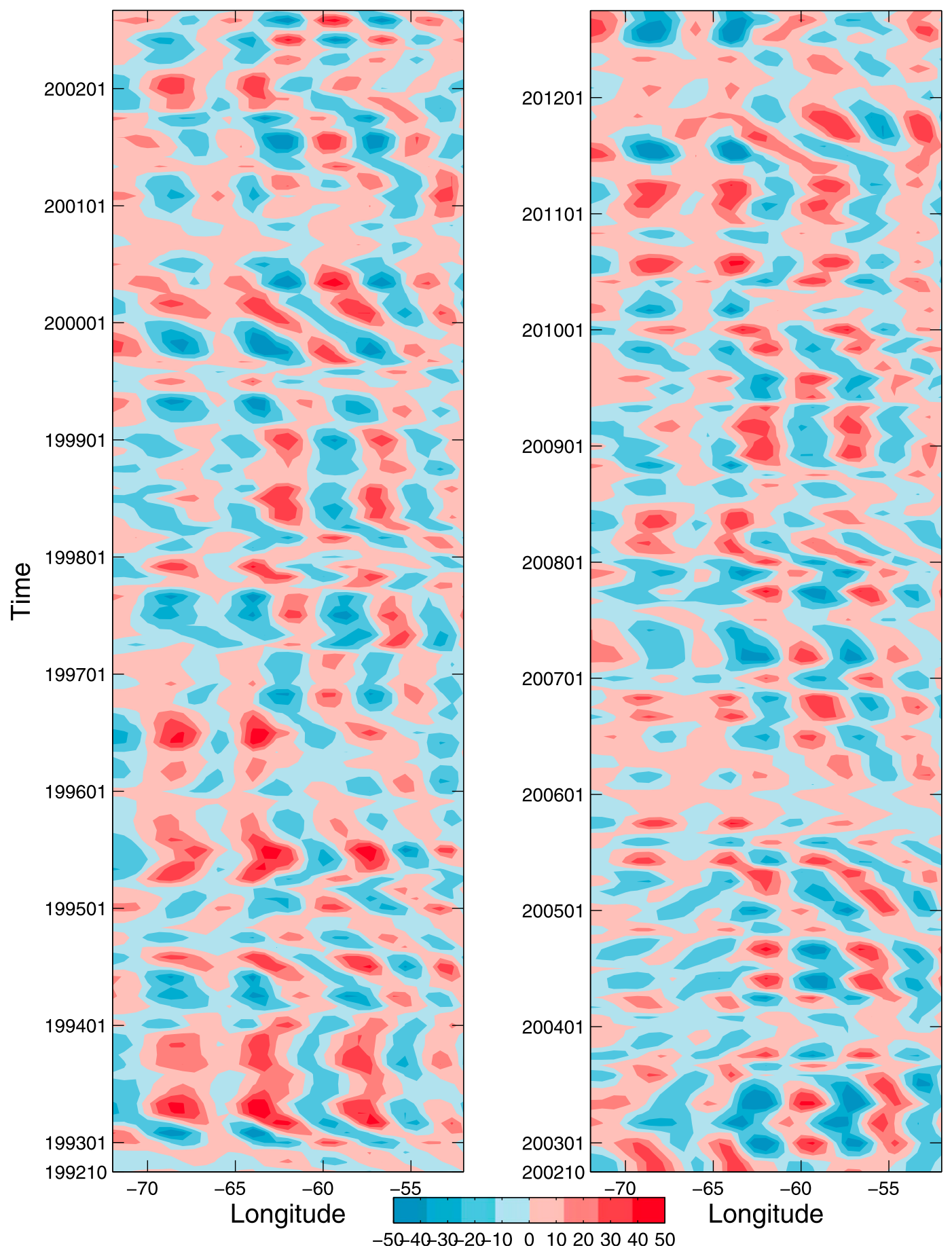

FIG. 7. Hovmöller diagram of modes 2,3 , and 4 of the whole region. (left) The first half of the time series and (right) the second half.

center of the strong horizontal temperature gradient of the GS. As it lies just to the north of the maximum flow at the surface, it is a good indicator of the northern side of the stream (Fuglister 1963). A detailed explanation on the wide use and quality of this index can be found in
Joyce et al. (2000), their section 5. In Fig. 8 an updated, seasonally resolved version of this index is plotted (black dashed) together with our simple and low-pass filtered 16-point GS index and mode 1 of the whole study area (red dashed, orange and blue line, respectively). This 


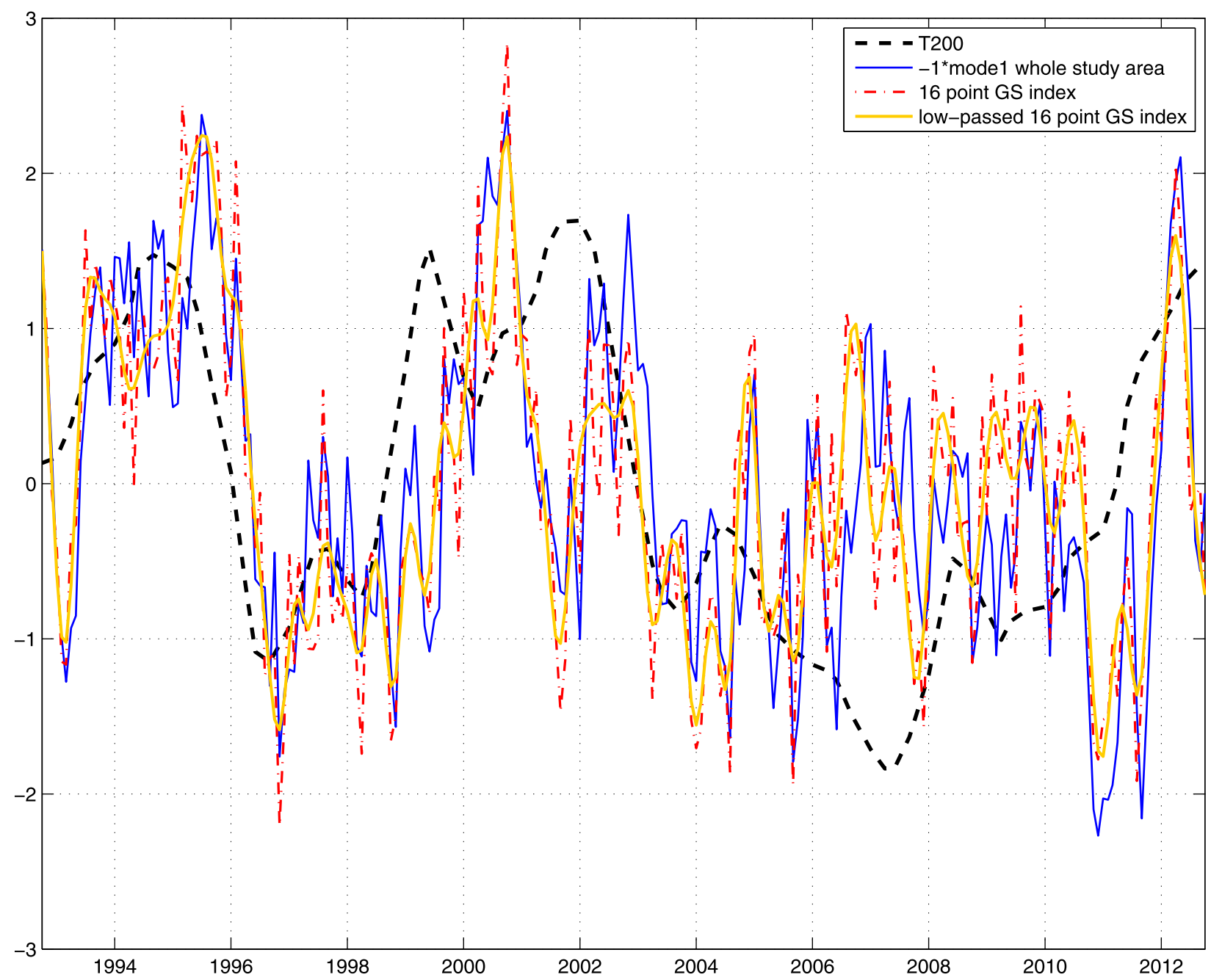

FIG. 8. Quarterly averaged first mode of the whole area (blue line), 16-point GS simple and low-pass index (red dashed and orange lines), and an updated 200-m temperature index following Joyce et al. (2000) (black dashed line).

new, $\mathrm{T}(200)$ based index has been obtained by reducing the amount of seasonal smoothing applied in previous estimates and is therefore a better index for comparison with the low-pass altimeter indices. In Fig. 8 during the period 1992-2000, a good agreement exists between both temperature and altimeter-based indices, but for the period 2000-11 the agreement becomes poorer. Differences between both indices can have different sources. The altimeter-based indices can be affected by oceanatmosphere interactions that are less observable at $200 \mathrm{~m}$. Another source of difference between the first and second periods may come from the mean profile used to compute SLA, as the mean altimeter surface and the interannual variability calculations use the mean sea surface over 1993-99 (Dibarboure et al. 2008). Another issue with this comparison was previously noted by Frankignoul et al. (2001): the T(200) index models indicate the climatological GS north wall location, not the GS high velocity core, which is better followed by the mean $18^{\circ} \mathrm{C}$ isotherm at $200 \mathrm{~m}$, rather than the mean $15^{\circ} \mathrm{C}$ isotherm used to define the north wall.

In Peña-Molino and Joyce (2008) the GS path was made from 10-day SSH anomalies along six descending tracks by searching for the maximum gradient. Then, they rotated AVISO surface geostrophic velocity anomalies onto the calculated mean GS path to analyze the GS shifts with EOFs. Figure 9 shows that all the various altimeter-based indices match, in spite their arising from different methods. For all of them, northwardsouthward shifts of the GS are represented by positive-negative temporal amplitudes. The fact that our indices (the whole area and the simple 16-point GS index) are in agreement with the one of Peña-Molino and Joyce (2008) implies that they are also indicative of 


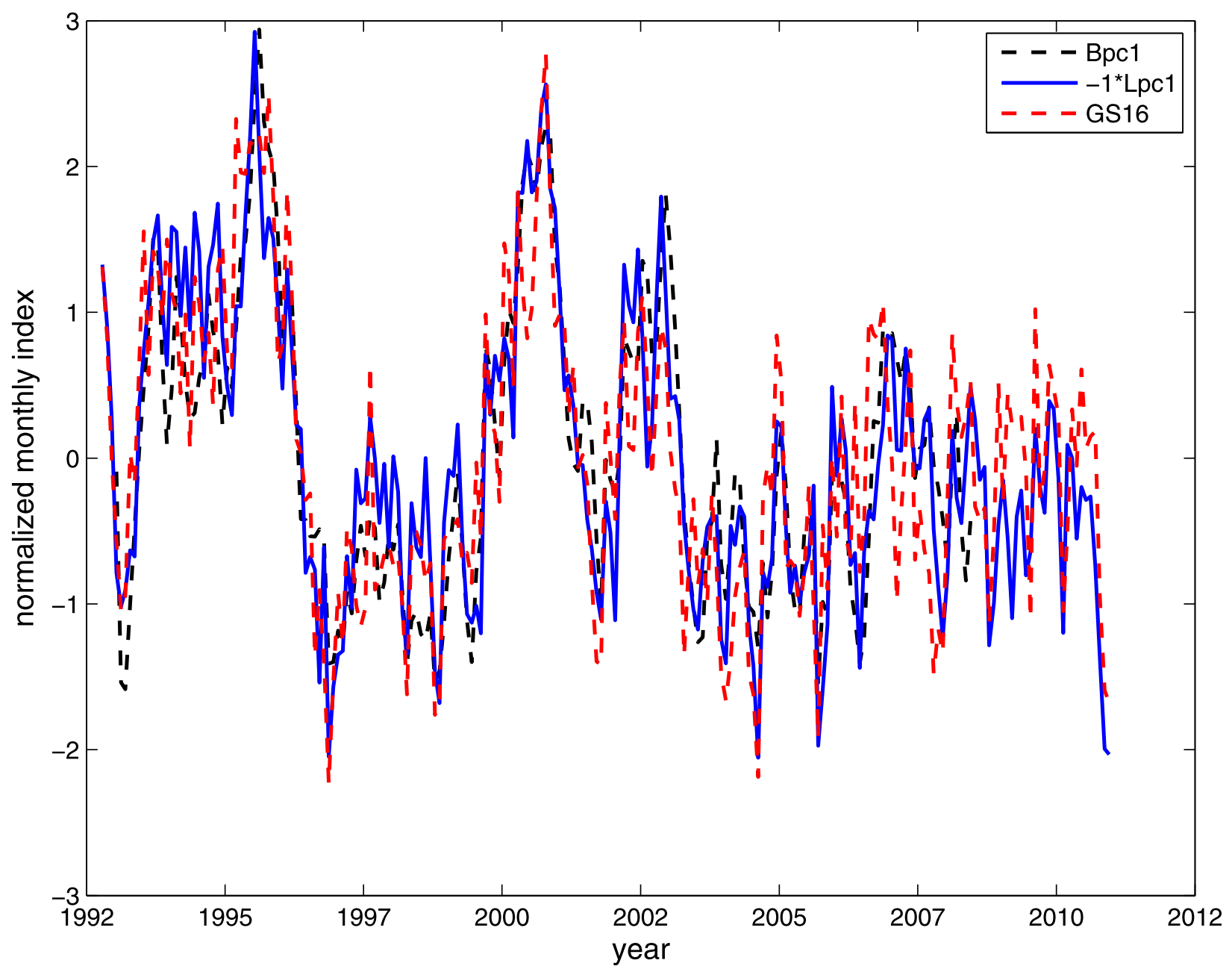

FIG. 9. First modes of Peña-Molino and Joyce (2008) (black dashed line) and $-1 \times$ mode 1 whole study area (blue line) together with the 16-point GS index (red dashed line).

changes in the SST anomalies and velocities in the Slope Water.

Trying to infer the source of the frequency peaks found with periods of approximately 5 and $2 \mathrm{yr}$ (64 and 25.6 months) shown in Fig. 6 for our 16-point GS index and whole study area mode 1, a comparison with the multivariate ENSO index (MEI) (October 2012, http://www. esrl.noaa.gov/psd/enso/mei/) has been made (Fig. 10). The highest correlation coefficients of 0.4 were obtained for time lags ranging from -30 to -28 months, for the low-pass filtered 16-point GS index and $-1 \times$ mode of the whole study area (Figs. 10b,c). This correlation indicates that the GS leads ENSO, which is in disagreement with everything previously reported. We believe that this correlation arises from the first northernmost displacement of the GS, which can be a consequence of the El Niño event of 1991, which occurred prior to our altimeter-based time series. In
Fig. 10a, it is observed that after both El Niños of 1997 and 2009, northward displacements of the GS occur. Computing the cross-correlation coefficients from January 1997 to avoid the first northward shift of the GS, we get two peaks in all the time series that cross the $90 \%$ confidence interval, both of them indicating that ENSO (MEI) leads the GS shifts (Fig. 10d). The negative correlation shows lags from $13(-0.4)$ to $14(-0.5)$ months for the comparison with the simple and lowpass filtered 16-point GS index, respectively, while 15 $(-0.4)$ months are observed for the comparison with the simple and low-pass filtered $-1 \times$ mode 1 whole study area. The second correlation peak is positive and is observed at lags of $33(0.3)$ and $32(0.4)$ months for the comparison with the simple and low-pass filtered 16-point GS index and at lags of 34 (0.3) and 33 (0.4) months for the comparison with simple and low-pass filtered $-1 \times$ mode 1 whole study area, respectively. This means that 

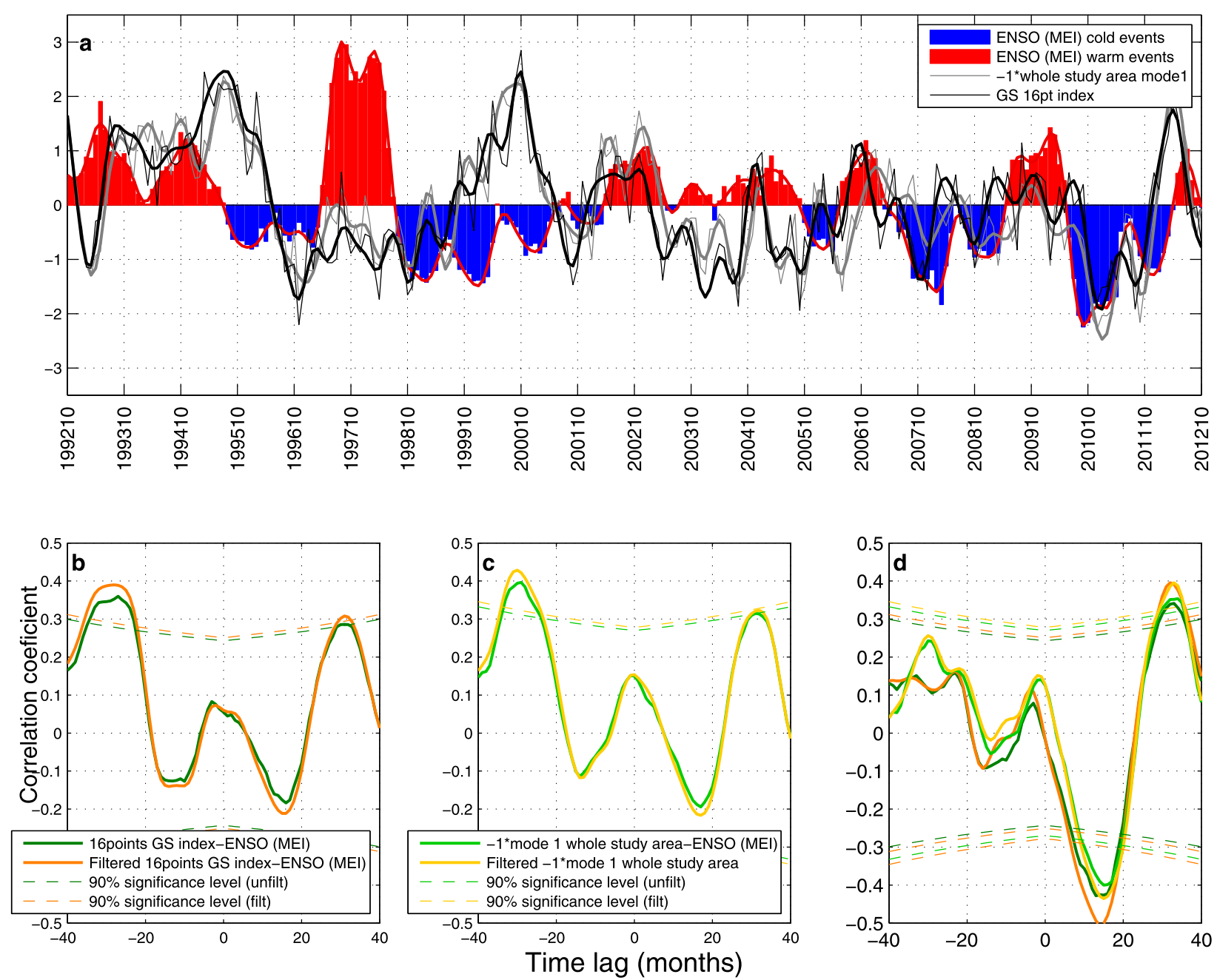

FIG. 10. (a) The time series of the ENSO (MEI) index (blue and red bars), of the $-1 \times$ mode 1 of the whole study area (thin gray lines), of the 16-point GS index (thin black line), and the resulting time series after passing a 6-month Butterworth filter of fifth order (thick lines). (b) Time-lagged cross-correlation coefficients are shown for the comparison with the simple (green lines) and low-pass 16-point GS index (orange lines) with a 90\% confidence interval (dashed orange and green lines). (c) As in (b), but the comparison is made with the simple (green lines) and low-pass $-1 \times$ mode 1 of the whole study area (yellow lines) (d) As in (b), (c), but estimated from January 1997. Positive time lags in (b)-(d) denote ENSO leading GS.

ENSO, which strongly affects the trade wind belt, could be a source of fluctuations for the GS (Taylor et al. 1998). The negative correlation with the shorter time lag indicates that, after ENSO peaks, the early response of the GS is to move south (Fig. 10a). Kwon et al. (2010) show that the winter after the ENSO peaks, the GS presents strong negative SST anomalies (see their Fig. 9), which is consistent with what we find for short positive GS lags. In addition, the second, positive cross correlation observed at approximately $2.5 \mathrm{yr}$ shows that at after El Niño events the late response of the GS is to shift northward (which can be clearly observed after the El Niño events of 1992,1997, and 2009 and a bit more roughly after the El Niño of 2004 in Fig. 10a). Taylor et al. (1998) reported that the GS is displaced northward following El Niño events by 2 yr.

Figure 6 shows periodicities of approximately $1-1.5 \mathrm{yr}$ in the three modes of the whole study area. Previous studies suggest that the GS varies annually, being more northerly in fall, more southerly in spring (Tracey and Watts 1986; Lee and Cornillon 1995; Rayner et al. 2011), and in its northernmost position in September (Lillibridge and Mariano 2012). This signal is masked with the seasonal steric heating described in the data section and in Fig. 2 making it difficult to confirm with our analyses.

The next periodicities of the three modes of the whole study area are in between semiannual and annual periods 

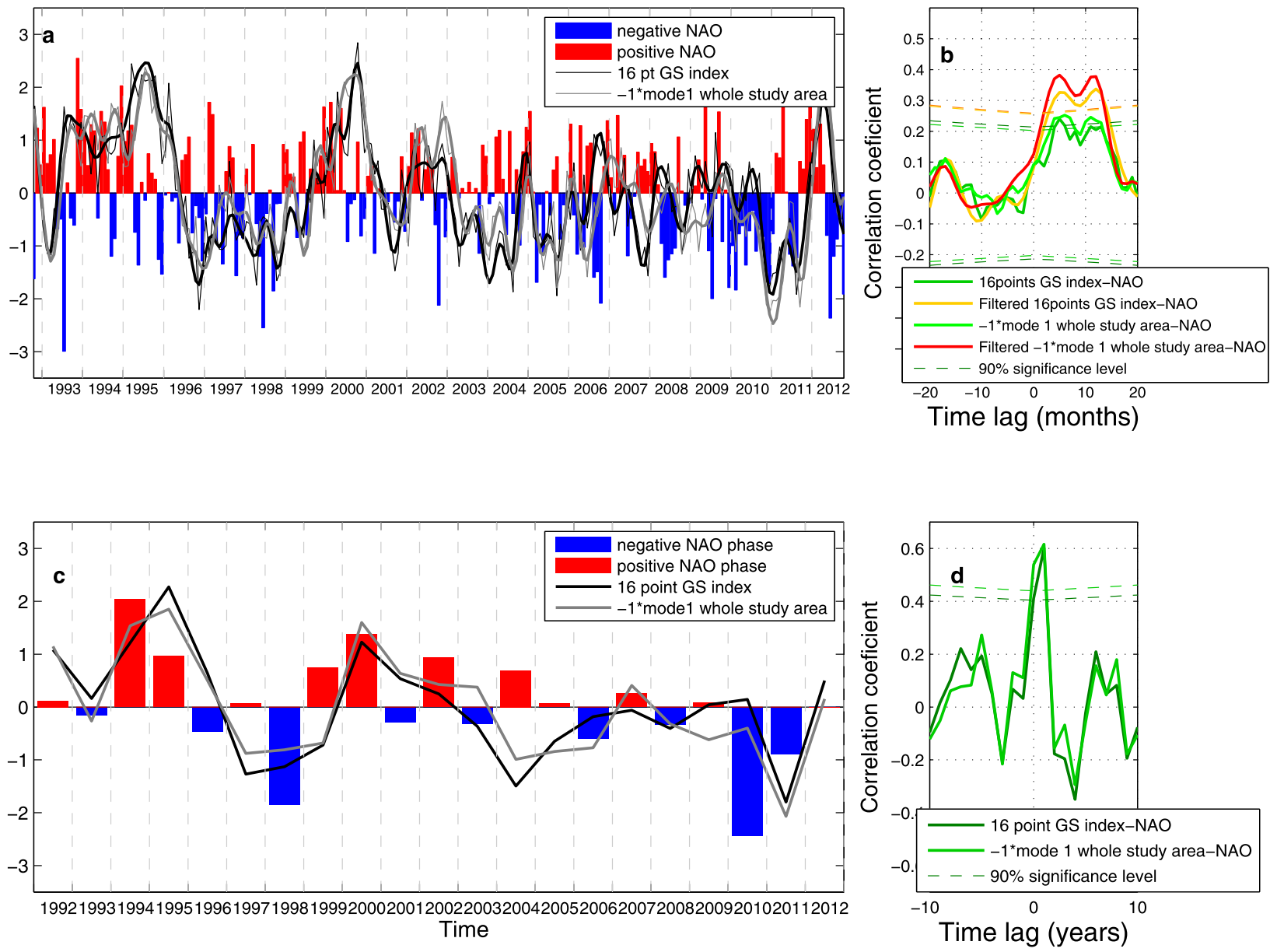

FIG. 11. (a) Comparison with the NAO shows the time series of the NAO index (blue and red bars) of the 16-point GS index (thin black line) and of the $-1 \times$ mode 1 whole study area (thin gray line) and the resulting time series after passing a 6-month Butterworth filter of fifth order (thick lines). (b) Time-lagged cross-correlation coefficients are shown for the comparison with the simple 16-point GS index and $-1 \times$ mode 1 whole study area unfiltered (dark and light green lines, respectively) and low-pass (yellow and red lines, respectively) with a $90 \%$ confidence interval (dashed lines). (c) Annual NAO (blue and red bars), simple annual 16-point GS index (black line) and simple annual $-1 \times$ mode 1 whole study area (gray line). (d) Annual time-lagged cross-correlation coefficients are shown for the comparison with the simple annual 16-point GS index time series (dark green line) and with the simple annual $-1 \times$ mode 1 whole study area (light green line) with a $90 \%$ confidence interval (dashed lines). Positive time lags in (b),(d) denote NAO leading GS.

(6-10 months) and they have been previously documented in Peña-Molino and Joyce (2008) and Lee and Cornillon (1995). These periods relate GS meanders with Rossby waves. In Osychny and Cornillon (2004) periods from 7 to 11 months are found between $34^{\circ}$ and $40^{\circ} \mathrm{N}$ for westward-propagating Rossby waves. Lee and Cornillon (1995) estimated a meandering index between $75^{\circ}$ and $60^{\circ} \mathrm{W}$, which fluctuated in time with a dominant period of approximately 9 months and they established that is close to the typical period of a first-mode, baroclinic, long Rossby wave at the mean latitude of the study area.

The forcing mechanism of the frequency peaks of modes 2 and 3 having periodicities from 1 to 5 months may be due to both meanders and DWBC variability. The periods smaller than 6 months of modes 2 and 3 of the whole study area represent a $65.01 \%$ and a $58.67 \%$ of their total variance. Lee (1994) using an 8-yr time series in the region between $75^{\circ}$ and $45^{\circ} \mathrm{W}$, estimated that the most probable period of meanders was 46 days. Savidge (2004) estimated that once the GS separates near Cape Hatteras, meanders have a period of 30-120 days, but also determined that the dominant DWBC energy is in the range of 20-60 days. Dewar and Bane (1985) suggest that DWBC could be supplying some of the energy necessary to develop the GS meanders in the region immediately downstream from Cape Hatteras.

The influence of DWBC over the GS has been previously documented. Thompson and Schmitz (1989) observed that the GS at the separation point is influenced by the DWBC. This is also observed in the eddy 

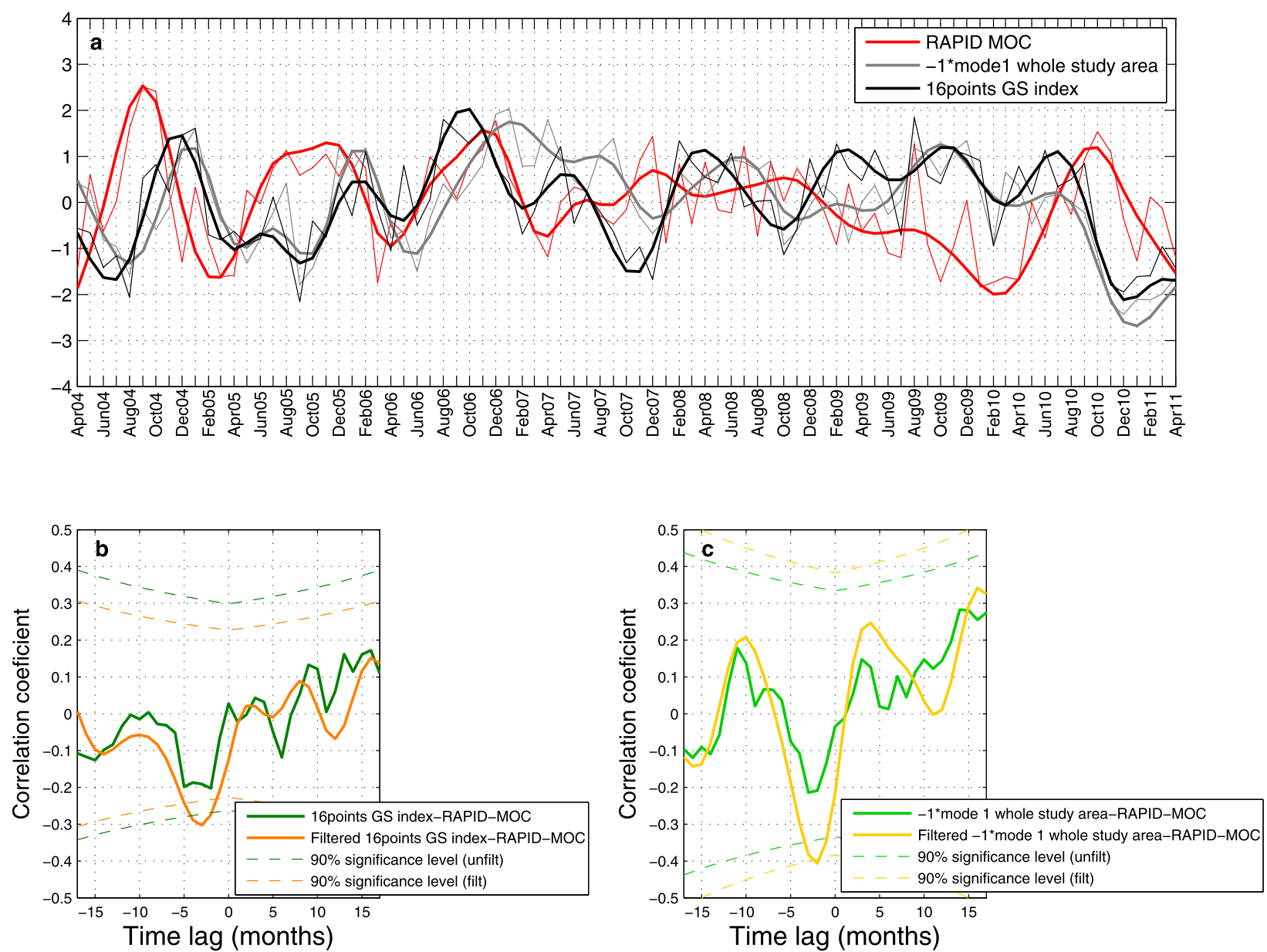

FIG. 12. (a) Comparison with the MOC of RAPID shows the time series of the RAPID-MOC index (thin red line) of the $-1 \times$ mode 1 whole study area (gray line) and of the 16-point GS index (thin black line) and the resulting time series after passing a 6-month Butterworth filter of the fifth order (thick lines). (b) Time-lagged cross-correlation coefficients are shown for the comparison with the simple and low-pass 16-point GS index (green and orange line) with a 90\% confidence interval (dashed lines). (c) As in (b), but for the comparison with the simple and low-pass $-1 \times$ mode 1 whole study area (light green line and yellow line). Negative time lags in (b), (c) denote GS leading RAPID-MOC.

resolving model of Bryan et al. (2007). Furthermore Spall (1996) and Joyce et al. (2000) add that these GS shifts are related to the water formation in the Labrador Sea, propagating down to the region of Cape Hatteras by advection in the DWBC. In Peña-Molino (2010) a periodicity of approximately 100 days from Line $\mathrm{W}$ current meters, was suggested, associated with fluctuations in the DWBC. Savidge (2004) determined that the dominant DWBC energy is in the range of 20-60 days.

The simple and low-pass filtered 16-point GS index and the $-1 \times$ mode 1 of the whole study are compared with the North Atlantic Oscillation (NAO) index (October 2012, http://www.cpc.ncep.noaa.gov/products/ precip/CWlink/pna/nao.shtml) and with the Atlantic meridional overturning circulation (AMOC) regarding the source of the interannual periods observed in Fig. 6 .
For the monthly comparison with the NAO index (Fig. 11a), low cross-correlation coefficients (0.2-0.3) with time lags of 5-12 months are estimated for the simple and low-pass filtered 16-point GS index (Fig. 11b). Similar behavior is observed for the comparison with simple and low-pass filtered $-1 \times$ mode 1 whole study area, where correlations of $0.2-0.4$ are observed at 6 and 5 months, respectively (Fig. 11b). In contrast, when the simple annual time series are computed (Fig. 11c) and compared between them, the correlation coefficient obtained is 0.6 at a GS time lag of $1 \mathrm{yr}$ (Fig. 11d). It has been previously recorded that during positive phases of the NAO the GS shifts north with lags from 1 (Joyce et al. 2000) to 2 yr (Taylor et al. 1998; Hameed 2004).

De Coëtlogon et al. (2006) and Joyce and Zhang (2010) argued for a connection between the AMOC 
and the GS path, such that the GS path was southerly when the AMOC was large. This was suggested in Peña-Molino and Joyce (2008) and strongly evident in the Geophysical Fluid Dynamics Laboratory (GFDL) 2.1 climate model (Zhang and Vallis 2007; Joyce and Zhang 2010). We have made use of a measured AMOC estimate at $26^{\circ} \mathrm{N}$ by the Rapid Climate Change (RAPID)-Meridional Overturning Circulation and Heat Flux Array (MOCHA) program (http://www.noc.soton. ac.uk/rapidmoc/), although this time series is only $7 \mathrm{yr}$ long at present (years 2004-11) (McCarthy et al. 2012). In Fig. 12 the AMOC has been averaged per month and standardized to compare with the GS index and with first mode of the whole study area. Looking into the timelagged cross-correlations figures (Figs. 12b,c) we find that only the low-pass filtered 16-point GS index and $-1 \times$ mode 1 of the whole study area crosses the $90 \%$ confidence interval. This crossing is observed at $-3(-0.3)$ and $-2(-0.4)$ month time lags, indicating that the GS shifts lead MOC changes and have the opposite sign. Since GS path changes lag by a few months circulation changes near $39^{\circ} \mathrm{N}$ (Joyce and Zhang 2010; Fig. 2c), this would imply that changes in the AMOC at $24^{\circ} \mathrm{N}$ are lagging those at $39^{\circ} \mathrm{N}$ by $4-6$ months, a result not previously reported. In spite of the low correlation coefficients estimated, it is observed that the GS shifts between 2010 and 2012 are the largest of the last decade and equal to the largest of the entire record (Fig. 4).

To conclude, we propose a 16-point altimeter-based GS index as a good indicator of the latitudinal shifts of the GS path. It is well correlated with the whole study area mode 1 either being unfiltered (0.8) or low-pass filtered (0.9) and it has been shown to be able to reproduce comparable cross correlations in comparison with climatological indices. The index can be quickly estimated and updated without changes in previous estimates and is a useful measurement of the large-scale shifts in the GS path, which can be related to climate variability (Joyce et al. 2009), to changes in some fish stocks (Nye et al. 2011), and keystone species (Borkman and Smayda 2009).

Acknowledgments. The first author will like to thank the Agencia Canaria de Investigación, Innovación y Sociedad de la Información (ACIISI) grant program of Apoyo al Personal Investigador en Formación and to thank the Woods Hole Oceanographic Institution (WHOI) for the opportunity to visit for an extended period as a guest student. The second author would like to acknowledge support for our "Line W" program of DWBC observations from NSF Grant OCE-0726720 to the Woods Hole Oceanographic Institution. Data from the RAPID-WATCH MOC monitoring project are funded by the Natural Environment Research Council and are freely available online (www.noc.soton.ac.uk/rapidmoc). We also want to acknowledge Alonso Hernández-Guerra and Pedro Vélez-Belchí for their continuous interests on the progress of this work and their total openness to questions.

\section{REFERENCES}

Bane, J. M., Jr., D. A. Brooks, and K. R. Lorenson, 1981: Synoptic observations of the three-dimensional structure and propagation of Gulf Stream meanders along the Carolina continental margin. J. Geophys. Res., 86, 6411-6425.

Borkman, D. G., and T. J. Smayda, 2009: Gulf Stream position and winter NAO as drivers of long-term variations in the bloom phenology of the diatom Skeletonema costatum "speciescomplex" in Narragansett Bay, RI, USA. J. Plankton Res., 31, 1407-1425, doi:10.1093/plankt/fbp072.

Bower, A. S., 1989: Potential vorticity balances and horizontal divergence along particle trajectories in Gulf Stream meanders east of Cape Hatteras. J. Phys. Oceanogr., 19, 1669-1681.

— from the Gulf Stream. J. Phys. Oceanogr., 22, 42-61.

Bryan, F. O., M. W. Hecht, and R. D. Smith, 2007: Resolution convergence and sensitivity studies with North Atlantic circulation models. Part I: The western boundary current system. Ocean Modell., 16, 141-159, doi:10.1016/j.ocemod.2006.08.005.

De Coëtlogon, G., C. Frankignoul, M. Bentsen, C. Delon, H. Haak, S. Masina, and A. Pardaens, 2006: Gulf Stream variability in five oceanic general circulation models. J. Phys. Oceanogr., 36, 2119-2135.

Dewar, W., and J. Bane, 1985: Gulf Stream dynamics. Part II: Eddy energetics at $73^{\circ}$ W. J. Phys. Oceanogr., 19, 1574-1588.

Dibarboure, G., O. Lauret, and F. Mertz, 2008: SSALTO/ DUACS user handbook: (M) SLA and (M) ADT near-real time and delayed time products. AVISO Rep. CLS-DOSNT 6, 39 pp.

Frankignoul, C., G. de Coetlogon, T. Joyce, and S. Dong, 2001: Gulf Stream variability and ocean-atmosphere interactions. J. Phys. Oceanogr., 31, 3516-3529.

Fuglister, F. C., 1955: Alternative analyses of current surveys. Deep-Sea Res., 2, 213-229, doi:10.1016/0146-6313(55)90026-5. , 1963: Gulf Stream '60. Prog. Oceanogr., 1, 265-373.

_ survey of the Gulf Stream. Tellus, 3, 1-14.

Gangopadhyay, A., P. Cornillon, and D. R. Watts, 1992: A test of the Parsons-Veronis hypothesis on the separation of the Gulf Stream. J. Phys. Oceanogr., 22, 1286-1286.

Hameed, S., 2004: The dominant influence of the Icelandic Low on the position of the Gulf Stream northwall. Geophys. Res. Lett., 31, L09303, doi:10.1029/2004GL019561.

Hernández-Guerra, A., and L. Nykjaer, 1997: Sea surface temperature variability off northwest Africa: 1981-1989. Int. J. Remote Sens., 18, 2539-2558, doi:10.1080/014311697217468.

Joyce, T. M., and R. Zhang, 2010: On the path of the Gulf Stream and the Atlantic meridional overturning circulation. J. Climate, 23, 3146-3154.

— C. Deser, and M. Spall, 2000: The relation between decadal variability of subtropical mode water and the North Atlantic Oscillation. J. Climate, 13, 2550-2569.

, Y.-O. Kwon, and L. Yu, 2009: On the relationship between synoptic wintertime atmospheric variability and path shifts in the Gulf Stream and the Kuroshio Extension. J. Climate, 22, 3177-3192. 
Kelly, K. A., and S. Gille, 1990: Gulf Stream surface transport and statistics at $69^{\circ}$ W. J. Geophys. Res., 95, 3149-3161.

Kwon, Y.-O., M. A. Alexander, N. A. Bond, C. Frankignoul, H. Nakamura, B. Qiu, and L. A. Thompson, 2010: Role of the Gulf Stream and Kuroshio-Oyashio systems in large-scale atmosphere-ocean interaction: A review. J. Climate, 23, 32493281.

Lee, T., 1994: Variability of the Gulf Stream path observed from satellite infrared images. Ph.D. dissertation, Graduate School of Oceanography, University of Rhode Island, $188 \mathrm{pp}$.

_ intensity and domain-wide lateral oscillations of the Gulf Stream. J. Geophys. Res., 100, 13603-13613.

Lillibridge, J. L., and A. J. Mariano, 2012: A statistical analysis of Gulf Stream variability from $18+$ years of altimetry data. Deep-Sea Res. II, 85, 1-20, doi:10.1016/j.dsr2.2012.07.034.

Marshall, J., H. Johnson, and J. Goodman, 2001: A study of the interaction of the North Atlantic Oscillation with ocean circulation. J. Climate, 14, 1399-1421.

McCarthy, G. and Coauthors, 2012: Observed interannual variability of the Atlantic meridional overturning circulation at $26.5^{\circ}$ N. Geophys. Res. Lett., 39, L19609, doi:10.1029/ 2012 GL052933.

Nakamura, M., and Y. Chao, 2000: Characteristics of threedimensional quasigeostrophic transient eddy propagation in the vicinity of a simulated Gulf Stream. J. Geophys. Res., 105 (C5), 11385-11406.

Nye, J. A., T. M. Joyce, Y.-O. Kwon, and J. S. Link, 2011: Silver hake tracks changes in northwest Atlantic circulation. Nature Commun., 2, 412-416, doi:10.1038/ncomms1420.

Osychny, V., and P. Cornillon, 2004: Properties of Rossby waves in the North Atlantic estimated from satellite data. J. Phys. Oceanogr., 34, 61-76.

Overland, J. E., and R. W. Preisendorfer, 1982: A significance test for principal components applied to a cyclone climatology. Mon. Wea. Rev., 110, 1-4.

Peña-Molino, B., 2010: Variability in the North Atlantic Deep Western Boundary Current: Upstream causes and downstream effects as observed at Line W. Ph.D. thesis, Woods Hole Oceanographic Institution, 174 pp.
— and T. M. Joyce, 2008: Variability in the slope water and its relation to the Gulf Stream path. Geophys. Res. Lett., 35, L03606, doi:10.1029/2007GL032183.

Preisendorfer, R. W., and C. D. Mobley, 1988: Principal Component Analysis in Meteorology and Oceanography. Elsevier Science, $444 \mathrm{pp}$.

Rayner, D., and Coauthors, 2011: Monitoring the Atlantic meridional overturning circulation. Deep-Sea Res. II, 58, 1744-1753, doi:10.1016/j.dsr2.2010.10.056.

Rossby, T., and R. Benway, 2000: Slow variations in mean path of the Gulf Stream east of Cape Hatteras. Geophys. Res. Lett., 27, $117-120$.

Savidge, D. K., 2004: Gulf Stream meander propagation past Cape Hatteras. J. Phys. Oceanogr., 34, 2073-2085.

Spall, M. A., 1996: Dynamics of the Gulf Stream/Deep western boundary current crossover. Texas A\&M University Dept. of Oceanography Part Working Collection 77843, 3952235001 .

Taylor, A. H., M. B. Jordan, and J. A. Stephens, 1998: Gulf Stream shifts following ENSO events. Nature, 393, 638-638.

Thompson, J., and W. Schmitz Jr., 1989: A limited-area model of the Gulf Stream: Design, initial experiments, and model-data intercomparison. J. Phys. Oceanogr., 19, 791-814.

Tracey, K., and D. Watts, 1986: On Gulf Stream meander characteristics near Cape Hatteras. J. Geophys. Res., 91, 75877602.

Watts, D. R., and W. E. Johns, 1982: Gulf Stream meanders: Observations on propagation and growth. J. Geophys. Res., 87, 9467-9476.

Welch, P., 1967: The use of fast Fourier transform for the estimation of power spectra: A method based on time averaging over short, modified periodograms. IEEE Trans. Audio Electroacoust., 15, 70-73.

Zhang, R., and G. K. Vallis, 2006: Impact of great salinity anomalies on the low-frequency variability of the North Atlantic climate. J. Climate, 19, 470-482.

_ and — 2007: The role of bottom vortex stretching on the path of the North Atlantic Western Boundary Current and on the northern recirculation gyre. J. Phys. Oceanogr., 37, 20532080 . 